\title{
The Economic Implications of Kimberlite Emplacement
}

\author{
Barbara H. Scott Smith \\ Scott-Smith Petrology Inc., 2555 Edgemont Boulevard, North Vancouver, BC, Canada V7R 2M9
}

\begin{abstract}
Introduction
The economics of primary diamond deposits are defined by volume, grade and stone value which are summarised in three dimensional geological models. Resource estimates based on the geological models are used to determine whether the diamonds present can be extracted economically. The volume, grade and stone value of the pre-emplacement magmas are determined by processes that take place in the mantle and during ascent towards surface. The final volume of a deposit, as well as the diamond distribution (grade and value), reflect the near-surface emplacement history of multiple batches of mantle-derived magmas, typically carrying different diamond populations. A comparison of available geological models reveals that distinct types of primary diamond deposits characterised by different shapes and infills reflect contrasting styles of emplacement. In this contribution, Canadian geological models together with qualitative and quantitative macroscopic petrography are used to demonstrate the economic consequences of emplacement.
\end{abstract}

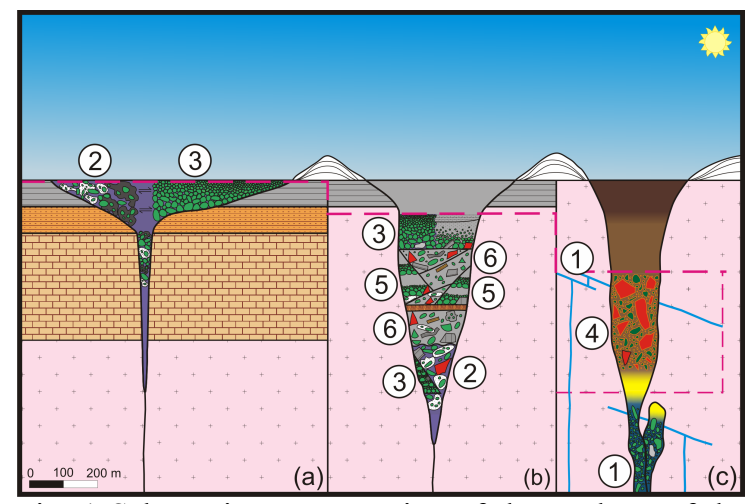

Fig. 1 Schematic representation of the geology of the three main types of kimberlite pipes in Canada (see Scott Smith 2008b for details). Different textural types of kimberlite are numbered in order of discussion. Pipe type (a) is dominated by pyroclastic kimberlite (PK\#2, \#3), (b) by resedimented volcaniclastic kimberlite (RVK\#5, \#6), and (c) by tuffisitic kimberlite breccia (TKB\#4), hypabyssal coherent kimberlite (HK\#1 sheet and pipe) with TK-HK transitional types (yellow).

\section{Geological Models}

Although each kimberlite body is unique, there are three distinct classes of kimberlite pipes in Canada each dominated by different textural varieties of kimberlite (Fig. 1). Summary models such as Fig. 1 provide the basis for extrapolating between data points and successfully applying predictive geology to the development of the geological models. The contrasting pipe shapes have obvious implications for the initial and post-erosional deposit volumes. Most phases of kimberlite within a deposit derive from archetypal kimberlite magmas, the nature of which is indicated by typical hypabyssal kimberlite (HK\#1 in Fig. 1, Fig. 2). Emplacement processes modify the distribution of the components, including diamond, which is reflected in the macroscopic petrography.

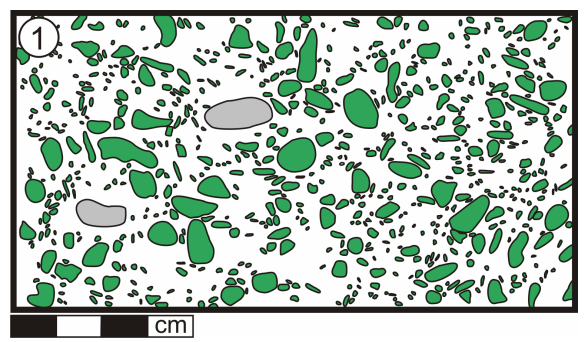

Fig. 2 Macroscopic constituents of typical hypabyssal kimberlite (HK\#1, Fig. 1). Green = olivine macrocryst; grey $=$ metasomatised xenolith; white $=$ crystalline matrix. Polished slab trace. Snap Lake sheet, NWT.

\section{Qualitative Macroscopic Petrography}

Schematic figures (Figs. 2-6) show the distribution of macroscopic components $(>0.5 \mathrm{~mm})$, fresh or altered olivine macrocrysts and xenoliths, in the different textural types of kimberlite shown in Fig. 1. The constituents from Fig. 2 were used to create Figs. 3 to 6 as a summary of observed textures and to mimic different modifications to the erupting magma (Fig. 2) that result from emplacement. The olivine population of pyroclastic kimberlite (PK) seldom resembles that of HK\#1 as illustrated by two end member types, PK\#2 and \#3 (Fig. 1). PK\#2 is composed mainly of juvenile lapilli which represent all of the components from Fig. 2 (Fig. 3, jlPK\#2). PK\#3 is composed of free olivines representing only the macroscopic components of Fig. 2 (Fig. 4, olPK\#3). The matrix of Fig. 2 was not incorporated into the olPK\#3, probably having formed ash removed by widespread pyroclastic sorting (Scott Smith 2008a). In contrast, the olivine population of tuffisitic kimberlite breccia (TKB\#4 in Fig. 1, Fig. 5) commonly resembles that of HK\#1 (Figs. 1, 2) except for dilution by varied and commonly large amounts of country rock xenoliths. Parts of pipes remaining vacant after the cessation of primary emplacement processes are usually infilled with resedimented volcaniclastic kimberlite (RVK, Fig. 1). Wide ranges of primary eruptive products, country rocks, surface materials and surface processes result in extremely diverse types of RVK with a certain range occurring in pipe (b) in Fig. 1 (RVK\#5 and \#6, Fig. 6). 
Figures 2 to 6 schematically illustrate the differences in abundance and distribution of the main macroscopic constituents, olivine and xenoliths, that result from the emplacement of the same magma as shown in Fig. 2. The petrographic features are quantified below using representative rock samples.

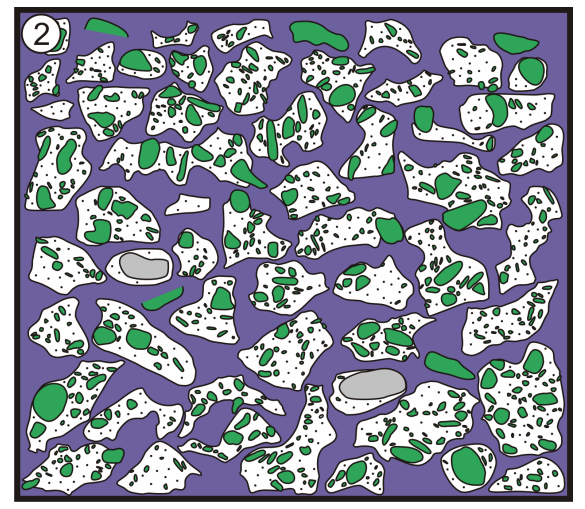

Fig. 3 Schematic illustration of massive unsorted pyroclastic kimberlite (PK) composed of looselypacked clast-supported ovoid-to-amoeboid juvenile lapilli (melt-bearing pyroclasts, j1PK\#2, Fig. 1). Scale, green and grey as Fig. 2; broken grain surfaces lack black outline; white + black dots $=$ quenched groundmass; purple $=$ interclast cement (features as described by Scott Smith 2008a). Juvenile lapilli represent jigsaw puzzle-like pieces of Fig. 2.

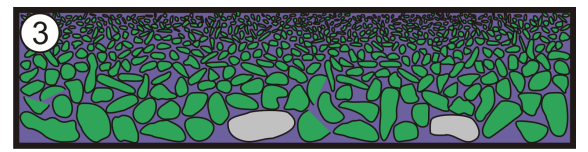

Fig. 4 Schematic illustration of normally-graded wellsorted pyroclastic kimberlite (PK) composed of clastsupported free olivine macrocrysts (devoid of melt; olPK\#3, Fig. 1). Scale, green and grey as Fig. 2; purple as Fig. 3 (features as described by Scott Smith 2008a). Includes all olivines and xenoliths from Fig. 2.

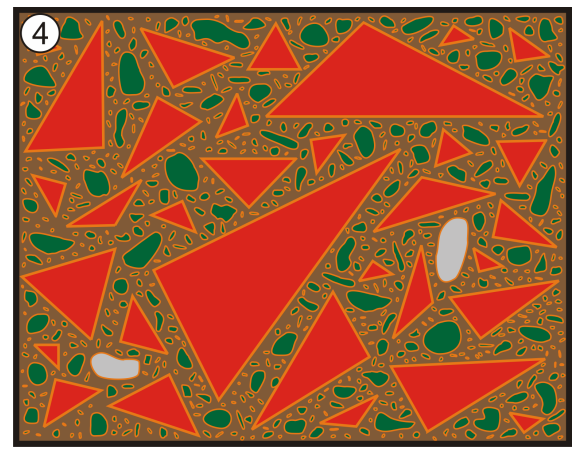

Fig. 5 Schematic illustration of tuffisitic kimberlite breccia (TKB\#4 in Fig. 1). Scale and grey as Fig. 2; red $=$ fresh country rock xenoliths; dark green = pseudomorphed olivine macrocrysts, orange = kimberlite selvages and mantles; brown = interclast matrix (features as described by Scott Smith 2008b, Hetman 2008, Mitchell et al. this volume). Country rock equivalent to half the area of Fig. 2 was fragmented into a wide range of clast sizes and mixed with the constituents from Fig. 2.

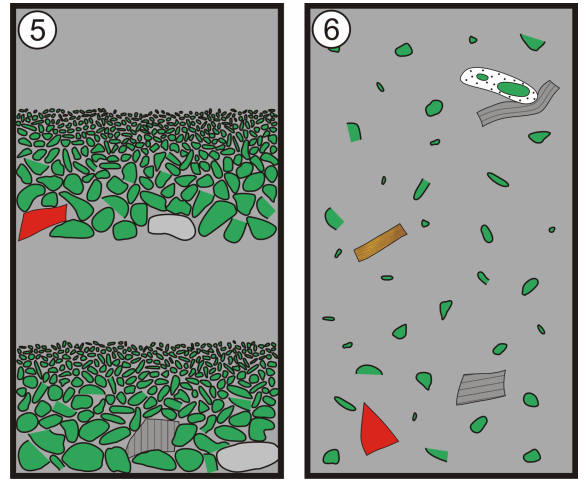

Fig. 6 Schematic illustration of contrasting types of resedimented volcaniclastic kimberlite (RVK\#5 and \#6, Fig. 1) particular to pipe (b). Scale, green and pale grey as Fig. 1; white + black dots as Fig. 3; red $=$ as Fig. 5, dark grey $=$ poorly consolidated shale xenoliths; brown = wood; medium grey $=$ matrix of mixed disaggregated shale (features as described by Scott Smith 2008b). RVK\#5 constituents are from olPK\#3 in Fig. 4 mixed with an equal proportion of disaggregated shale plus minor xenoliths. RVK\#6, unrelated to Figs. $2-5$, shows extreme dilution of primary constituents.

\begin{tabular}{|l|c|c|c|c|}
\hline \multirow{2}{*}{ Texture (Fig.\#) } & \multicolumn{2}{|c|}{ Olivine } & \multicolumn{2}{c|}{ Xenoliths } \\
\cline { 2 - 5 } & Fig. & Sample & Fig. & Sample \\
\hline HK\#1 sheet (2) & 28 & 31 & 2 & 1 \\
\hline HK\#1 pipe & nd & 27 & nd & 1 \\
\hline jlPK\#2 (3) & 19 & 21 & 1 & $<1$ \\
\hline olPK\#3 (4) & 59 & up to 50 & 3 & 1 \\
\hline TKB\#4 (5) & 18 & 12,11 & 31 & 25,30 \\
\hline TKt & nd & 17 & nd & 19 \\
\hline RVK\#5 (6) & 49 & nd & 4 & nd \\
\hline RVK\#6 (6) & 4 & nd & 3 & nd \\
\hline
\end{tabular}

Table 1 Modal abundance (\%) of macroscopic constituents $(>0.5 \mathrm{~mm})$. Texture from Fig. 1, Fig.\# is corresponding figure (Figs. 2-6). nd = not determined.

\section{Quantitative Macroscopic Petrography}

Twenty one samples were selected to be representative of the textural types illustrated in Figs. 1 to 6 : HK\#1 sheet (Fig. 1), HK\#1 pipe and TKt from the transition and two of TKB\#4 (47-299m, MPV-02-111C, Tuzo, Gahcho Kué; Hetman et al. 2004), one jlPK\#2 and fifteen samples of an olPK\#3 megagraded bed $(160.9 \mathrm{~m}$ 175-1, 116-282m 140-21, respectively, Fort á la Corne, Scott Smith 2008a). The TKB\#4 and olPK\#3-related samples each derive from single phases of kimberlite. Samples of RVK were not included because of their infinite variability. The macroscopic constituents $>0.5 \mathrm{~mm}$ in size were traced on polished slabs $(10,008$ olivines, 544 xenoliths) and their abundance and size measured using image analysis software.

The olivine abundances of Figs. 2-6 and the representative samples are summarised in Table 1 . The sheet and pipe HK\#1 are similar. The olivine abundance in $\mathrm{jlPK} \# 2$ and $\mathrm{TKB} \# 4$ are two thirds and half that of $\mathrm{HK}$, respectively, as a consequence of the increased volume of the final rock relative to the original magma. In $\mathrm{j} 1 \mathrm{PK} \# 2$ this results from the pore 
space between loosely-packed irregularly-shaped pyroclasts (Fig. 3). In TKB\#4, the olivine abundance is inversely proportional to the abundance of country rock xenoliths (Fig. 5). The proportion of xenoliths increases from the pipe HK\#1 to TKt to TKB\#4 from 1 to 17 to $25-31$ modal $\%$, the latter being comparable to Fig. 5. The abundance of total olivines in the schematic graded bed of olPK\#3 of Fig. 3 is double that of HK\#1. The samples, however, derive from a megagraded bed at least $180 \mathrm{~m}$ thick. Individual samples vary significantly from $<1$ modal $\%$ near the top, where the rock is dominated by components $<0.5 \mathrm{~mm}$ in size, up to 50 modal $\%$ in the deeper coarser parts (Fig. 7). The olivine abundance in most of the samples is different from that of HK\#1 but, importantly, the combined data for all samples are comparable to HK\#1. The latter shows that the megagraded bed formed from a single phase of typical kimberlite. The modal abundances of olivine in the megagraded bed vary with the grain size.

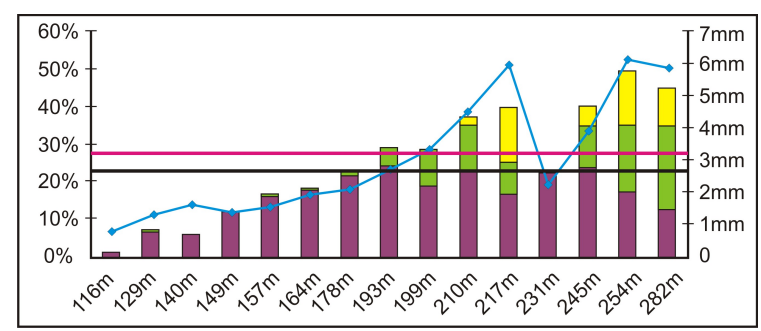

Fig. 7 Samples of a megagraded bed of olPK\#3 showing (i) olivine modal abundance (left axis, grain sizes: purple $0.5-2 \mathrm{~mm}$, green $2-5 \mathrm{~mm}$, yellow $>5 \mathrm{~mm}$ ), (ii) average olivine modal \% of all samples combined (black line), (iii) average size (right axis) of the 20 largest olivines (blue line). Magenta line is modal abundance of HK\#1 pipe (from Table 1).

The size distribution of olivine macrocrysts in the representative samples is shown in Fig. 8. Individual samples of the megagraded bed of olPK\#3 show substantial differences in the size distribution, from finer to coarser than $\mathrm{HK} \# 1$. The combined data of all the samples of the megagraded bed, however, are comparable to HK\#1 again indicating derivation from a single phase of typical kimberlite. The combined data also represent thin graded beds of olPK\#3 (as Fig. 3). The size distribution of the jlPK\#2 and TKB\#4 and TKt are similar to the HK\#1. The further modification of olivines shapes and sizes by processes such as breakage are not discussed here.

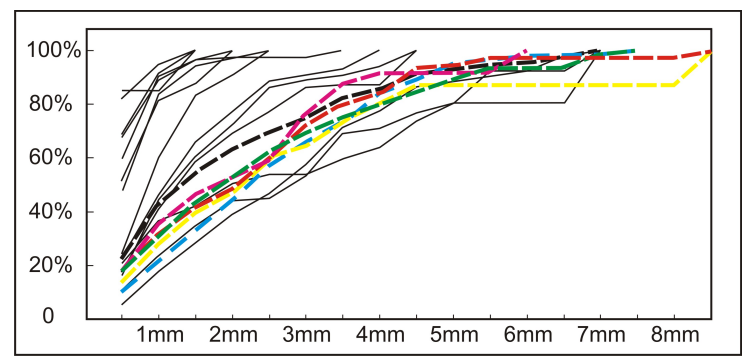

Fig. 8 Cumulative olivine modal abundance for the representative samples (grouped in $0.5 \mathrm{~mm}$ size classes). Solid lines: individual samples of the megagraded bed of olPK\#3. Dashed lines: black = all samples of olPK\#3 combined; blue $=$ HK\#1 pipe, yellow $=\mathrm{TKt}$, red and magenta $=\mathrm{TKB} \# 4$, green $=$ jlPK\#2 (numbers are textures in Fig. 1).

\section{Conclusions}

The data presented here indicate fundamental differences between contrasting textural types of kimberlite and thus the emplacement processes that formed them. The data for the majority of PKs is consistent with conventional extrusive pyroclastic eruption processes. The minimal modification of the olivine size distribution in TKB and TKt is consistent with formation by subsurface processes without sorting (Mitchell et al. this volume).

Olivine macrocrysts and macrodiamonds are both mantle xenocrysts of similar size and properties. Olivine data such as that presented here can be used, together with geology and petrography, in the economic evaluation of primary diamond deposits to improve the prediction of diamond grade and distribution within, and between, kimberlite units for resource estimates and to prioritise evaluation work. For example, based on Table 1 the predicted postemplacement grades for a 100 carats per hundred tonnes (cpht) kimberlite magma would be $\sim 100 \mathrm{cpht}$ for pipe or sheet HK\#1, $\sim 65 \mathrm{cpht}$ for j1PK\#2 and $\sim 50 \mathrm{cpht}$ for TKB\#4 and up to $200 \mathrm{cpht}$ for olPK\#3. Variations in the olivine populations are commonly mirrored in the diamond content (e.g. Berryman et al. 2004). The practical advantage of olivine macrocrysts is that they are relatively easy to measure and are much more abundant than diamond as well as other mantle-derived xenocrysts (e.g. garnet) which occur in trace amounts. Further, measurements can be made using rapid visual estimates and the variations, although a consequence of diverse emplacement, can be determined without knowledge of the textures. Understanding the emplacement processes, however, improves the degree of confidence in any predictions.

\section{References}

Berryman, A.K., Scott Smith, B.H., Jellicoe, B., 2004. Geology and diamond distribution of the 140/141 kimberlite, Fort a la Corne, central Saskatchewan, Canada. Lithos 76, 99-114.

Hetman, C.M., Scott Smith, B.H., Paul J.L, Winter, F.W., 2004. Geology of the Gahcho Kué kimberlite pipes, NWT, Canada: Root to diatreme magmatic transition zones. Lithos 76, 51-74.

Hetman, C.M., 2008. Tuffisitic kimberlite (TK): a Canadian perspective on a distinctive textural variety of kimberlite. Journal of Volcanology and Geothermal Research 174, 57-67.

Mitchell, R.H., Skinner, E.M.W., Scott Smith, B.H., 2008. Tuffisitic kimberlites: mineralogical characteristics relevant to their formation. This volume.

Scott Smith, B.H., 2008a. The Fort á la Corne kimberlites, Saskatchewan, Canada: geology, emplacement and economics. Journal of the Geological Society of India 71, 11-55.

Scott Smith, B.H., 2008b. Canadian kimberlites: geological characteristics relevant to emplacement. Journal of Volcanology and Geothermal Research 174, 9-19. 